\title{
Abstracts
}

\section{P03.06 SEXUAL EXCHANGES AND COERCION AMONG UNDERGRADUATE STUDENTS IN NIGERIA: IMPLICATIONS FOR SEXUALLY TRANSMITTED INFECTIONS}

Adeyemi Oluwagbemiga*. Federal University Oye-Ekiti

$10.1136 /$ sextrans-2015-052270.234

Background Numerous studies have been documented in Nigeria to assess the magnitude of sexual coercion there is limited literature that linked sexual coercion with sexual exchanges, and vulnerability among students. This study therefore examines the relationship between sexual exchanges and coercion with its implication on Sexually Transmitted Infections (STI) among undergraduate students in the study area.

Methods A multi-stage random sampling procedure was employed in administration of 1458 questionnaires. Three levels of analysis were used for this study.

Results From the survey, half of the respondents had their first sexual experiences before age 16 years while $40 \%$ of the respondents had sexual intercourse with two or more partners in the last six months preceding the survey. Two-thirds of the respondents did not use condom in their last sexual intercourse. The study established a significant relationship between sexual coercion and ever had STIs, period of relationship, use of condom, having multiple partners and STI treatment behaviour. While the logistic regression shows that respondents aged 15-19 years are 2.568 times more likely to be coerced $\left(\mathrm{P}\right.$ value $\mathrm{X}^{2}=$ 0.00 CI 1.717-3.839) when compared with the reference category aged 20-24 years. There is a positive relationship between sexual coercion and sexual gratification; those who received gifts (both materials and money) are 1.947 times more likely to experience sexual coercion when compared with those who receive nothing.

Conclusion and recommendation Violence limits women's ability to manage their reproductive health and exposes them to sexually transmitted diseases. There is need for holistic approach to the issue of sexual coercion especially among young females based on the health consequences and the psychological trauma for the experience they did not prepare for. There is need for policy action and health education against sexual coercion in the study area.

\section{P03.07 MITIGATING THE IMPACT OF HIVIAIDS AMONG IN AND OUT OF SCHOOL YOUTH THROUGH PEER EDUCATION USING FAMILY LIFE HIV EDUCATION IN FEDERAL CAPITAL TERRITORY ABUJA NIGERIA}

Falilu Opeyemi Agbaje*, Farinloye Makanjuola. OROL Youth Empowerment Initiative

\subsection{6/sextrans-2015-052270.235}

HIV AIDS has systematically permeated the entire Nigerian social fabric, affecting males and females in both urban and rural areas, as well as adolescent young people.

This paper presents findings from an evaluation of a HIV prevention program designed to determine the effects of HIV prevention intervention (HPI) on in school youths in AMAM Local Government Area Abuja Nigeria.

Data were collected from 75 trained peer educators from 3 Schools in AMAC Local Government Area FCT Abuja Nigeria and also 100 in school youths who were not trained. Data were also collected at the beginning and end of the intervention among 950 in school youths that were reached with peer education in 3 Schools and also among other 1100 in school youths from 3 other schools that were not reached with the program using qualitative and quantitative research methods.

The findings revealed that the programme had several positive effects on the students such as increase in knowledge of HIV/AIDS, adoption of preventive behaviour and acquisition of life skills. The quantitative data shows the knowledge of the respondents have increased by $71 \%$ at the end of the intervention and the result also shows that the students trained as peer educators have higher knowledge of HIV prevention and life skills than those who were not trained.

The quantitative and qualitative data show that the project has produced several positive multiplier effects on the knowledge and behaviour of youths. The findings also show It is necessary to focus on young people because they are at the centre of the HIV/AIDS epidemic. The project shows that Peer education is one of the best approaches to providing comprehensive knowledge on HIV/AIDS/STIs and related issues, as it provide an excellent environment for effective peer-to-peer learning. There is therefore the need to sustain and even expand the program such that we can reach out to other youths in other areas of the city and even other states of the country.

\section{P03.08 PREVAILING MYTHS AND MISCONCEPTIONS AND EFFECT OF INTERVENTION IN CHANGING THE ATTITUDE OF SECONDARY SCHOOL STUDENTS OF SOUTH DELHI REGARDING HIVIAIDS AND POSITIVE PERSONS}

SK Badhan*, Rani Usha, Badhan Sonal, SN Ojha. HKMC Trust, Sarita Vihar, New Delhi

\subsection{6/sextrans-2015-052270.236}

Background Despite detailed information available regarding HIV infection, a lot of misconceptions and the infection is still regarded as a taboo and the positive person is discriminated. Youth can play an important role in removing this taboo.

Methods The NGO is involved in giving life skills education to school children. This study part of the same involved students of class IX onwards selected from eight schools of South Delhi.

Students were administered anonymous semi structured pre tested pro forma seeking information regarding age, sex, various myths/misconceptions regarding HIV infection and their attitude towards HIV positive person. After a detailed brainstorming interactive session the students were given one hour break and they were asked to visit the hall where IEC material in the form of leaflets and charts was displayed. After the break same pro forma marked ' $\mathrm{B}$ ' was given to be filled.

Results A total of 400 students were given the pro forma and there were 8 refusals, giving a response rate of $98 \%$. Of these 192 males and 200 females responded. Myths/misconceptions regarding transmission were: through blood donation 154 (39.28\%), swimming in common pool 225 (57.39\%), playing together $278(70.91 \%)$ and shaking hands $202(51.53 \%)$ and after intervention came down respectively to 54 (13.77\%), 98 (25.0\%), 95 (24.23\%) and 89 (22.70\%).

Attitude towards a positive person was adjudged by asking fear of eating 276 (70.4\%), having friendship 191 (48.7\%), allowed to attend school $270(68.9 \%)$ and by taking care 319 (81.4\%), and the same changed respectively after intervention to: 116 (29.59\%), 331 (84.43\%), 352 (89.79\%) and 376 (95.91\%). 